\title{
A luta das mulheres pela educação diante de questões que envolvem o mundo do trabalho, classe, etnia e gênero
}

The fighting of women for education in connection with the world of work, class, ethnicity and gender

\author{
Kalina Gondim de Oliveira ${ }^{1}$ \\ Clarice Zientarski ${ }^{2}$
}

\begin{abstract}
RESUMO
O trabalho busca contribuir com o debate sobre a temática da luta das mulheres pelo direito à educação, evidenciando interações que envolvem Classe e Gênero. Trata-se de pesquisa bibliográfica e documental e, conclui que a luta das mulheres é a luta contra o capitalismo, o racismo, a precarização do trabalho e outras formas de discriminação.
\end{abstract}

PALAVRAS-CHAVE: Luta das Mulheres. Educação. Mundo do trabalho.

Classe. Gênero.

\begin{abstract}
The paper seeks to contribute to the debate on the theme of the struggle of women for the right to education, highlighting interactions involving Class and Gender. It is a bibliographical and documentary research and concludes that the struggle of women is the struggle against capitalism, racism, precarious work and other forms of discrimination.
\end{abstract}

KEYWORDS: Women's struggle. Education. World of Work. Class. Gender.

\section{Introdução}

O trabalho resulta de uma pesquisa bibliográfica e documental, que a partir de uma visão histórica e dialética, pretende contribuir com o debate sobre a temática da luta das mulheres pelo direito à educação. Neste prisma,

\footnotetext{
${ }^{1}$ Doutoranda em Educação pela Universidade Federal do Ceará. Professora de Ensino Superior. Email: kalinnagondim@hotmail.com.

2 Professora do Departamento da Universidade Federal do Ceará. Professora e Pesquisadora da Pós-Graduação em Educação Brasileira. E-mail: cariazientarski@yahoo.com.br.
} 
parte da premissa de que ao tematizar o mundo do trabalho, com destaque no trabalho feminino, evidenciam-se interações imprescindíveis que envolvem Classe e Gênero.

A discussão visa também ampliar as análises e reflexões em torno do tema, rompendo com ideias fundadas no cotidiano, que constituindo o senso comum, reforçam as visões alienadas e ideologizadas. Essas ideologias intangíveis e difusas, se reproduzem de forma eficaz e abrangente, mergulhando em todos os domínios da existência humana, são as ideologias que sedimentam os discursos, as representações e obstaculizam a percepção profunda da realidade social. Neste enfoque, em relação à ideologia, compreende-se com Marx e Engels em a Ideologia Alemã, que ela se apresenta como um meio que é utilizado pela Classe dominante, com o objetivo de manter o domínio sobre as outras Classes e impor as suas ideias construindo uma falsa consciência (MARX; ENGELS, 1977).

As ideologias cumprem, portanto, o papel de desestimular e dissuadir as transformações sociais, naturalizando o que constitui produto da história humana. No caso específico das mulheres as múltiplas ideologias do sistema se aglutinam à ideologia que impinge às mulheres um papel passivo e secundário na história. A relevância da temática ora apresentada se dá por sua atualidade e urgência histórica dada a situação de exclusão vivenciada pelas mulheres.

As questões relacionadas às mulheres são diversas e complexas e na atualidade se avolumam os debates teóricos que são impulsionados pela problemática social, buscando dar respostas aos dilemas femininos, onde esses se intercruzam com as problemáticas de Classe e Etnia. No campo prático também é percebido o aumento considerável do número de movimentos sociais que a nível local e transnacional lutam por maior inclusão das mulheres nos campos do trabalho, educação e política, bem como visam desconstruir a cultura misógina que está na base dos atos violentos perpetrados por homens contra as mulheres.

No entanto, Solnit (2017), aponta que os movimentos feministas cada vez mais vêm incluindo alguns homens como colaboradores, o que de acordo 
com a autora revelaria uma maior consciência de que o tema da mulher diz respeito a todos. A centralidade adquirida por esses movimentos e a visibilidade ganha por um Gênero que historicamente foi invisibilizado, trouxe como consequência a quebra de um discurso unilateral centrado nas histórias escritas por homens, onde nessas o feminino era retratado como um Gênero infantil, irracional e naturalmente voltado para questões da esfera privada. A emergência de uma contra narrativa que deu voz as mulheres instaurou a pluralidade de visões e a polifonia. Perrot (2015, p. 17) explica o porquê da invisibilidade feminina:

Em primeiro lugar, porque as mulheres são menos vistas no espaço público, único que, por muito tempo merecia interesse e relato. Elas atuam em famílias confinadas em casa, ou no que serve de casa. São invisíveis. Em muitas sociedades, a invisibilidade e o silêncio das mulheres fazem parte da ordem das coisas. É a garantia de uma cidade tranquila. Sua aparição em grupo causa medo. Entre os gregos é a stasis, a desordem. Sua fala em público é indecente.

Virgínia Woolf, em seu clássico "Um teto todo seu” (2014), analisa os obstáculos impostos pela estrutura social às mulheres que desejavam exercitar seus talentos para a escrita. Apesar da densidade da escrita dessas autoras, convém esclarecer que os textos que retratam a condição de subalternização das mulheres e da desigualdade de poder entre os Gêneros, é um movimento que tem sua gênese em um passado longínquo, e para conhecer esse passado, se faz necessário revisitar obras antigas para a partir daí confrontar presente, passado e futuro, memória e projeto. Nesse panorama, pode-se citar o livro "A sujeição das mulheres" de John Stuart Mill, publicado no ano de 1869. A singularidade dessa obra reside no fato de ela ter sido escrita por um homem que, contrariamente aos costumes da época, fazia a defesa da igualdade entre os sexos denunciando os privilégios dos homens sobre as mulheres, ainda que algumas limitações sejam percebidas nessa obra, ela constitui um marco e um embrião para os textos do presente.

Stuart Mill, já no século XIX, enxergava o crescimento dos movimentos das mulheres na defesa do direito à escolarização. $\mathrm{O}$ autor esclarece que: 
A reinvindicação das mulheres em serem uniformemente educadas como os homens nos mesmos ramos de conhecimentos está crescendo intensamente e com grande perspectiva de sucesso, enquanto que a exigência por sua aceitação em profissões e ocupações até aqui negadas a elas, fica mais urgente a cada ano. (MILL, 2006, p. 36).

O fato é que naquela época já crescia também o número de partidos políticos que traziam como bandeira a luta das mulheres pelo direito ao voto. E foi em torno dessas lutas políticas que Olympe de Gouges, uma feminista contemporânea à Revolução Francesa, acabou sendo executada em 1791. O crime de Olympe foi ter construído a defesa da Declaração dos Direitos da mulher e da Cidadã. Essa declaração não foi aprovada, ao contrário do que ocorreu com a Declaração dos Direitos do Homem e do Cidadão. Esse fato demonstra claramente que a revolução francesa (1789-1799), inspirada nos valores iluministas tinha suas limitações e que os ideais de educação pública, gratuita, laica e universal seriam apenas ideias abstratas para determinadas classes sociais, sexo e etnia.

Nesse mesmo cenário, Charles M. Talleyrand-Périgord, citado por Wollstonecraft (2015), elaborou um relatório sobre o ensino público no qual Talleyrand expos o modelo de educação voltado para as mulheres diametralmente oposto ao pensado para os homens. O autor defende que:

Não busquemos a solução para um problema já resolvido. Eduquemos as mulheres de tal modo que não aspirem às vantagens que a constituição lhes nega, mas para que conheçam e apreciem as vantagens garantidas a elas (...). O destino dos homens é viver no palco do mundo. A educação pública lhes convém, pois desde cedo, ela coloca diante de seus olhos todas as cenas da vida: apenas as proporções são diferentes. A casa paterna é melhor para a educação das mulheres; elas devem aprender menos sobre a necessidade de lidar com os interesses dos outros e habituar-se mais a uma vida calma e isolada. (WOLLSTONECRAFT, 2015, p. 13). 
O papel excludente e conservador reservado à educação, revela manchas que se reproduzem e estão presentes até os dias atuais, dados que derivam da própria estrutura excludente e discriminatória do sistema capitalista. Marx e Engels em a Ideologia Alemã, sublinham que "a primeira divisão do trabalho é a que se faz entre o homem e a mulher para a procriação dos filhos" (MARX; ENGELS, 1977, p.70). Neste enfoque, se compreende que cabia à mulher os cuidados com a casa e os filhos e, ao homem a manutenção da prole.

Compreender, portanto, a lógica maior e a dinâmica de um sistema é fundamental para não compactuar com visões superficiais e atomizadas que reduzem as questões femininas à identidade e diferença de Gênero, não questionando as desigualdades no acesso a produção, ao poder político e educação, essas desigualdades que se processam a um nível objetivo é que produzem subjetividades heterodeterminadas. O racismo, o sexismo e a discriminação de Classe que perpassa o campo da linguagem e das relações sociais são o reflexo de uma estrutura societária segregadora e excludente.

\section{1 - Classe social, etnia e geopolítica: questões que envolvem as mulheres e a educação}

A desigualdade educacional não se limita às questões de Gênero, ao contrário, se reproduz nas questões de classe, onde aos trabalhadores é destinada uma educação em quantidade e qualidade diferentes ofertada a educação das elites. No tocante às questões de Etnia também é sabido que a população negra até os dias atuais exibe os menores índices de escolarização e essas estatísticas têm sua matriz no sistema escravocrata alicerçado no trabalho forçado, penoso e nas múltiplas exclusões de negros e negras tanto nos campos da política quanto da educação. Essas hierarquias perpassam o campo institucional e as diferentes relações sociais.

Alguns indivíduos condensam em torno de si múltiplos fatores discriminatórios como é o caso das mulheres negras trabalhadoras. Estas pertencem a uma Classe social a um Gênero e a uma Etnia marcadas por exploração econômica e dominação política. Esses processos pautados nos 
mais diferentes níveis de expropriação explicam a posição dessas mulheres na base da pirâmide social brasileira, onde recebem os piores salários e trabalham majoritariamente em empregos precarizados. Nesse prisma, é a mulher negra que melhor simboliza a total ausência de direitos sociais no Brasil.

Além das questões de Classe e Etnia, o panorama geopolítico influencia sobremaneira as condições das mulheres no mundo. Em áreas geográficas como o Iêmen, Irã, Paquistão, entre outras, marcadas pela pobreza, guerras e fundamentalismos, as mulheres vivenciam situações extremas de opressão e, nesse quadro a proibição de que as meninas frequentarem uma escola é um fator central para a subalternização da mulher.

Nessas sociedades é comum mulheres andarem com livros escondidos sob seus véus. No ano de 2008, o Paquistão sob o regime do Talibã, viu as escolas femininas serem fechadas e posteriormente queimadas. Nesse contexto, Malala Yousafzai que se transformou em um ícone na luta pelo direito das meninas à educação afirmou:

No final de 2008, o assessor de Fazlullah, Maulana Shah Dauran, anunciou no rádio que todas as escolas femininas seriam fechadas. A partir de 15 de janeiro advertiu ele, as meninas não deveriam mais ir à escola (...). Embora amássemos estudar, só nos demos conta do quanto a educação é importante quando o Talibã tentou nos roubar esse direito. Frequentar a escola, ler, fazer nossos deveres de casa não era apenas um modo de passar o tempo. Era nosso futuro (...). o Talibã podia tomar nossa canetas e nossos livros, mas não podia impedir nossas mentes de pensar. (YOUSAFZAI, 2013, p. 44).

A contra face da proibição das meninas em frequentar uma escola é o trabalho infantil, o casamento e a maternidade precoces além da violência doméstica. Na história da educação brasileira também é notória a exclusão das mulheres ao direito de conhecer. Ribeiro (1997, p. 2), sinaliza por meio de versos que: "mulher que sabe muito é mulher atrapalhada, para ser mãe de 
família, saiba pouco ou saiba nada." e "[...]a mulher honrada deve ser sempre calada”. Esta situação pode ser comprovada quando se verifica que nas escolas jesuíticas apenas homens livres frequentavam, ainda que as mulheres representassem metade da população.

$\mathrm{O}$ acesso à escolarização formal foi um processo lento e gradual. Em 1827, na época do Império, foi autorizada a existência das escolas femininas de primeiras letras e em 1879, com a Lei Leôncio de Carvalho as mulheres tiveram acesso ao ensino superior. No entanto, a primeira mulher a portar um diploma de nível superior foi uma realidade no Brasil após trinta anos da promulgação dessa lei.

Nísia Floresta, uma grande feminista da época, alertou para o fato de que em 1852 havia no Brasil 44 mil alunos matriculados nas escolas públicas, onde destes apenas 8.433 eram mulheres. Além da desigualdade numérica, existia um abismo quanto aos objetivos escolares de homens e mulheres.

Essa visão associa o trabalho feminino ao magistério, tendo em vista que à função de professora colocavam-se as características tidas como intrínsecas ao gênero feminino, a saber: A docilidade, ternura, paciência. Hypólito analisa que:

Dentre as características que permitiram o ingresso maciço das mulheres na profissão de ensinar ou dentre as características femininas que se adequavam às da profissão podem ser destacadas: a proximidade das atividades do magistério com as exigidas para as funções de mãe; as "habilidades" femininas que permitem um desempenho mais eficaz de uma profissão que tem como função cuidar de crianças; a possibilidade de compatibilização de horários entre o magistério e o trabalho doméstico, já que aquele pode ser realizado em um turno; a aceitação social para que as mulheres pudessem exercer essa profissão (HYPÓLITO, 1997, p. 55).

O magistério, portanto, era uma das poucas, senão a única profissão que podia ser seguida pelas mulheres, devido ao patriarcado que impunha relações assistenciais entre homens e mulheres, ainda, por meio de um intenso processo de dominação, produzia diferenças "naturais" entre os contornos de ser e agir feminino e masculino (GONDIN, 2016). Quase que naturalmente as mulheres foram se 
inserindo em profissões nas quais a questão do cuidado possui grande relevância. Para as mulheres as qualidades "naturais" do Gênero feminino, tais como: a paciência, a docilidade e a propensão em cuidar é mais relevante que as habilidades cognitivas e técnicas.

Assim, a partir das questões elencadas acima, compreende-se que as relações de gênero precisam ser analisadas conjuntamente com as relações de classe, pois o fenômeno da inserção das mulheres no mundo do trabalho se materializou em um momento histórico de franco desenvolvimento capitalista. Assim, ao se organizar uma sociedade pautada na dominação e exploração de uma classe sobre outra, as relações entre homens e mulheres não fugiram a essa lógica, pois, "o primeiro antagonismo de classe que apareceu na história coincide com o desenvolvimento no antagonismo entre o homem e a mulher" (ENGELS, 1997, p. 70).

Ao gênero masculino, destarte, estava reservado um currículo voltado à preparação para o mundo, trabalho bifurcado em dois caminhos: a administração pública e o mundo dos negócios. Já para as mulheres, o modelo escolar enfatizava o papel da maternidade e o cuidado com a família. Estas dificuldades em relação ao trabalho historicamente foram postas às mulheres e à medida que foram ocupando espaços, a sua luta se tornou mais árdua.

\section{2- $\mathrm{O}$ mundo do trabalho e o mundo das mulheres na conjuntura atual}

Contemporaneamente, é comum mulheres estarem em guetos profissionais, elas são maiorias em profissões como: enfermeiras, professoras da educação básica e, principalmente, empregadas domésticas. Estas últimas carregam toda sorte de estigmas e preconceitos, o que representa o retrato mais fidedigno do trabalho precarizado, desregulamentado e que guarda o ranço da escravidão exercido em sua maioria por mulheres negras. $\mathrm{O}$ trabalho doméstico esperou até o ano de 2015, para assistir ao advento de uma lei que obrigasse a essas trabalhadoras terem assegurados seus direitos trabalhistas. Deve-se ressaltar, entretanto, que o trabalho doméstico é exercido por todas as mulheres em seus lares e consiste em um trabalho monótono, desgastante e totalmente gratuito, simbolizando para as mulheres que trabalham fora, uma carga adicional de deveres. Apesar da centralidade na vida das mulheres 
e, na reprodução do sistema como um todo, a complexa problemática do trabalho doméstico permanece no vácuo. Fougeyrollas-Schwebel (2009, p.144) analisa que:

Essa invisibilidade aparece como resultado de dois grandes fatores; para todas as correntes de pensamento, a família nos anos 1960 é definida como um lugar de consumo; com a industrialização, ela teria perdido toda função ou papel produtivo. O segundo fator decorre de que as diferenças de funções e atividades entre mulheres e homens são percebidas antes de tudo como "naturais". Fala-se de responsabilidades familiares sem aprofundar o questionamento.

A análise acerca do trabalho feminino ganhou novos contornos com a crise capitalista de 1970, e com o movimento da globalização. As crises no sistema capitalista são algo recorrente, no entanto, a crise que se deflagrou nos anos de 1970 revelou-se mais aguda e profunda que as crises antecedentes.

A atual dinâmica capitalista caracterizada por um grande movimento de mundialização imprimiu um caráter global à sua crise, onde os efeitos de destrutividade foram sentidos tanto no centro quanto na periferia do sistema. No entanto, cabe ressaltar que esses efeitos se materializavam de forma diferenciada entre os países, dado que estes têm realidades econômicas diferentes derivadas da divisão internacional do trabalho e de relações políticas desiguais. A crise capitalista desponta no elevado índice de desemprego e subemprego, revelando de forma sem precedentes o caráter supérfluo da mercadoria-trabalhador. Nesse cenário, os empregos femininos aparecem como os mais precarizados e instáveis.

Antunes afirma que:

As relações entre Gênero e Classe nos permitem constatar que no universo do mundo produtivo e reprodutivo vivenciamos também a efetivação de uma construção social sexuada, onde os homens e as mulheres que trabalham são, desde a família e a escola, diferentemente qualificados e capacitados para o ingresso no mercado 
de trabalho. E o capitalismo tem sabido apropriar-se desigualmente dessa divisão sexual do trabalho. (ANTUNES, 2000, p. 109.).

No cenário da crise estrutural, o capital expande seus mercados a fim de ampliar seus movimentos de acumulação. Nesse tocante, a ideologia da globalização cumpre um papel ideológico importante, dado que espalha ao nível de senso comum a ideia de quebra irrestrita de barreiras e proteções econômicas, desterritorialização e fluxo homogeneizado de capitais e pessoas. A globalização alterou a dinâmica do espaço e trouxe a necessidade de produzir novos conceitos e categorias interpretativas. No entanto, deve-se observar que o fenômeno da globalização produziu muita falácia e manipulação, bem como ampliou a pobreza, concentrou o poder e exclui espaços geográficos os denominados quarto mundo (CASTELLS, 1999, p.53).

A globalização interpela a figura do Estado nação e seus ideólogos preveem a obsolescência e fenecimento daquela figura que outrora foi um elemento chave para a expansão capitalista. É importante frisar que a defesa da inutilidade do Estado é apenas mais uma retórica, pois o que observamos no panorama mundial por um lado, são os países centrais com a defesa de suas soberanias nacionais e monopólios e, de outro, os países periféricos esvaziados no seu papel de provedor de políticas públicas, com soberanias abaladas e elevado nível de endividamento externo. Furtado (1998, p.64), ao refletir acerca da globalização, expõe:

A globalização tem consequências negativas marcantes, das quais destaco a crescente vulnerabilidade externa e a gravação da exclusão social (...). O grande desafio consiste em minimizar os males resultantes da perda de comando provocada pela globalização, o que requer políticas que tenham a especificidade do país.

Ao confrontar a soberania dos países periféricos, os países hegemônicos trabalham cada vez mais com o conceito de governança. Esta se caracteriza pela multiplicidade de atores que têm o poder de definir os rumos das questões atuais. Entre esses atores salienta-se os organismos internacionais, 
notadamente o Banco Mundial (BM) e o Fundo Monetário Internacional (FMI) que, controlado pelos países mais ricos do mundo, impõem suas regras, receitas e políticas aos países pobres. Estas são caraterísticas do modo de produção capitalista, que conforme salienta Ianni (1988), é um sistema que mercantiliza as relações, as pessoas e as coisas e, acima de tudo, transforma as pessoas em mercadoria.

Nesse contexto, no mundo do trabalho e na constituição deste espaço societário à mulher vai ser destinado um papel importante, com sua inserção profissional, como força de trabalho para a valorização do capital. No que se relaciona ao trabalho feminino, Antunes (2000 p. 109), defende que: "é evidente que a ampliação do trabalho feminino no mundo produtivo das últimas décadas é parte do processo de emancipação parcial das mulheres, isto se materializa "tanto em relação à sociedade de classe quanto às inúmeras formas de opressão masculina, que se fundamentaram na tradicional divisão sexual do trabalho".

Antunes vai adiante em sua análise e assegura que a classe trabalhadora no contexto atual é "crescentemente composta" por segmentos "diferenciados, mulheres e terceirizados e/ou precarizados (e ainda mais frequentemente por mulheres terceirizadas)" (p.108). Ainda, como consequência a "expansão do trabalho feminino tem se verificado no trabalho mais precarizado", por exemplo, nos "trabalhos em regime part- time", em grande parte na "informalidade" e, com "desníveis salariais" mais marcantes". Antunes pontua ao citar o "Le Monde", em seu número especial de 1990, que as mulheres realizam "jornadas mais prolongadas". Com isto, evidenciam-se as "interações necessárias entre "Gênero e Classe, particularmente quando se tematiza o universo do mundo do trabalho". (ANTUNES, 2000, p. 109).

Nesse panorama global, a questão da mulher, sua escolarização e sua posição no mundo do trabalho não podem mais ser analisadas apenas a nível local. Os destinos das mulheres no mundo perpassam um conjunto de metas globais, que resultam de uma agenda mundial, pensada de forma unilateral pelos países centrais, reduzindo a complexidade e pluralidade das questões femininas. 


\section{3- Os organismos internacionais e a temática das mulheres}

A transnacionalização das questões femininas teve início com a institucionalização da década da mulher (1975-1985), pela Organização das Nações Unidas (ONU). A partir daí se sucederam a Convenção sobre a Eliminação de Todas as Formas de Discriminação contra a Mulher, de 1979 e a Declaração de Pequim, de 1995, adotada pela IV Conferência Mundial sobre as Mulheres. Ainda na década de 1990, a Conferência Mundial sobre Educação para Todos, patrocinada por organismos internacionais. Entre as metas da Conferência Mundial sobre Educação estavam a universalização do ensino fundamental, o maior protagonismo da comunidade e a focalização na educação das meninas. A maior atenção à educação das meninas se deu em um cenário no qual o Banco Mundial (BM) estimava que 72 milhões de crianças no mundo não frequentam a escola e destas crianças 54\% são meninas.

Segundo o BM a educação ajuda no empoderamento feminino e seria o instrumento mais eficaz para quebrar o ciclo da pobreza, dado que segundo o Banco Mundial a mulher com acesso à escolaridade reduz o número de gestações, a mortalidade infantil, bem como tem acesso a maiores oportunidades de emprego.

Neste enfoque, conforme o Relatório sobre o desenvolvimento mundial de Igualdade de Gênero e Desenvolvimento de 2012, a Cúpula dos Objetivos do Desenvolvimento do Milênio (ODM) de 2010, concluiu a "adoção de um plano de ação global para alcançar os oito objetivos até 2015”. Adotou também uma "resolução de apelo à ação para assegurar a paridade de Gênero" que se materializariam "em oportunidades econômicas, de educação e saúde, e tomada de decisões por meio da integração de uma perspectiva de Gênero na formulação de políticas para o desenvolvimento”. (BM, 2012, p.4).

No documento salienta-se ainda que a "resolução e o plano de ação refletem a crença da comunidade internacional de desenvolvimento de que a igualdade de Gênero e o empoderamento das mulheres são objetivos de 
desenvolvimento por direito próprio (ODM 3 e 5)". Destaca que os objetivos funcionam "como importantes canais para a obtenção de outros ODMs e de reduzirem a pobreza relacionada e não relacionada com a renda". Ainda, salienta que a "igualdade de Gênero e o empoderamento de mulheres ajudam a promover o ensino fundamental básico (ODM 2)," e contribui para "reduzir a mortalidade de crianças com menos de cinco anos (ODM 4), melhorar a saúde materna (ODM 5) e a reduzir a probabilidade de contrair HIV/AIDS (ODM6)”. (BM. 2012. p. 4).

É observado que a visão de pobreza para o Banco Mundial é um fenômeno particular e que deve ser rompido a partir de estratégias individuais. A pobreza nesse raciocínio é deslocada das questões históricas e estruturais. Não é percebida como resultado de inúmeros processos e relações assimétricas. É interessante também a visão redentora e fetichista que a educação assume, vendida como panaceia para todas as crises e disfunções sociais.

Neste sentido, O BM anuncia: "Três prioridades orientam nosso trabalho com os países": 1) "acelerar o crescimento econômico sustentável e inclusivo; 2) "investir nas pessoas para construir capital humano"; 3) "promover a resiliência a choques e ameaças globais". (BM. 2017, p.14). E, para reduzir a pobreza o Banco Mundial afirma que: "Trabalhamos com formuladores de políticas no desenvolvimento de mercados, instituições e economias estáveis, equitativas e eficientes". Com esta assertiva pode-se compreender qual a lógica que permeia a formulação das políticas, ou seja, a prioridade se coloca no indivíduo e não o coletivo, o que inclui as politicas para as mulheres quando indica que: "O empoderamento das mulheres nos negócios e dos jovens com empregos pode ajudar a melhorar as perspectivas econômicas do país". (B>M> 2017, p.37).

É válido neste sentido, apontar a contradição exposta no discurso do BM que importa o conceito de empoderamento feminino que se traduz em poder pessoal, ascensão econômica e busca de igualdade entre homens e mulheres invertendo־o e reduzindo־o ao aumento de número de escolaridade e o foco da atenção das mulheres aos cuidados com a família, o que se traduz 
em uma reedição de modelos educacionais pautados em estereótipos de Gênero, no qual cabe às mulheres o papel exclusivo de cuidadora. $\mathrm{O}$ atual presidente do Banco Mundial Jim Young Kim investiu 2,5 bilhões em projetos de educação feminina, o que demonstra o interesse da instituição em "educar" as meninas. Desde então, "recursos têm sido comprometidos em vários lugares, inclusive no nordeste da Nigéria e na Província Punjab no Paquistão". (BM. 2017, p. 22).

O prognóstico é que o BM continuará investindo pesadamente em educação feminina, com a ajuda de fundações empresariais e instituições norte-americanas. A atenção direcionada à educação das meninas e o volume de recursos financeiros empregados deveriam ser motivo de comemoração para aqueles que lutam pelo direito das mulheres à escolarização. No entanto, uma análise mais acurada revela nas entrelinhas os interesses não declarados do Banco Mundial, que se traduz na preocupação com o avanço demográfico nos países periféricos e com o risco de ingovernabilidade devido ao aumento da pobreza, instabilidade e convulsão social. Nesse sentido, controlar o aumento populacional via cooptação e sedução das mulheres é de suma importância, é aí que a retórica do empoderamento se faz necessária.

Ao colocar sobre o ombro das mulheres a difícil tarefa de aplacar um fenômeno tão complexo como é a pobreza dos países periféricos, o Banco Mundial revela a incongruência entre o que defende para as mulheres dos países pobres e as políticas de ajuste estrutural que impõe a esses países. Ajustes esses que, invariavelmente, produzem mais pobreza, além do que esvazia o Estado com suas políticas de privatizar, desnacionalizar e de abertura econômica.

Percebe-se que o Banco Mundial tenta fragilizar o movimento das mulheres que vem crescendo de forma substancial, declarando a potência das políticas de base e questionando frontalmente a política institucional, calcada na democracia representativa distante e impermeável à participação popular. O movimento das mulheres questiona o sistema capitalista em seus pressupostos, demonstrando que a questão das mulheres e de outras minorias é uma questão da sociedade e de suas desigualdades, divisões e 
contraposições. Nesta perspectiva, Rago (2004), contribui no sentido de se compreender que o movimento das mulheres não é isolado do conjunto das lutas políticas e sociais, "devido ao seu potencial profundamente subversivo, desestabilizador, crítico, intempestivo, assim como pela vontade humano, livre e solidário, seguramente não apenas para as mulheres”. (RAGO, 2004, p. 36).

Ao lançar luz nas raízes dos problemas atuais apontando para a lógica do capital, o movimento das mulheres precisa não apenas ser atacado, mas desmobilizado e cooptado. O Banco Mundial enquanto organismo financeiro apologista do capitalismo e controlado pelos países mais ricos do mundo e suas empresas transnacionais precisa por meio de uma potente sedução heterodeterminar os objetivos dos movimentos femininos não os confrontando mas, esvaziando suas pautas e vendendo o conceito de empoderamento feminino, baseado em uma ascensão econômica e social das mulheres, como um produto individual dentro da lógica capitalista. Importando para o Gênero feminino o modelo de sucesso vendido para os homens, a saber, um sucesso que se adapta ao sistema e que introjeta suas ideologias.

O Banco Mundial dedica às mulheres uma visão de mundo calcada na sinergia entre ideologia de Classe que subjetiva as mulheres a buscar sua empregabilidade e a se lançar no empreendedorismo, ocultando que o desemprego hodierno é um desemprego estrutural que, para além de como pensam alguns, não é produto de um determinismo tecnológico, mas é ,antes de tudo, o resultado de uma política que visa concentrar capital. Aglutinada a essa ideologia de Classe está a ideologia que perpassa a questão de Gênero, ao enfatizar o papel feminino como naturalmente passivo, ainda, em parte, voltado para o lar e para o cuidado com a família.

Os valores defendidos por esses dois ideários, aparentemente se revelam dissonantes, mas só aparentemente, pois na essência eles se fortalecem mutuamente, promovendo uma crise identitária nas mulheres, ao passo que anunciam sua pseudo emancipação que tem como pilar o empoderamento (leia-se poder pessoal), ao mesmo tempo em que sinaliza para as mulheres, que seu papel mais relevante no mundo é cuidar de sua família, 
filhos e, indiretamente, contribuir para uma sociedade mais harmônica, fundando assim uma retrospectiva à época remota. É o velho e o novo, o arcaico e o moderno da sociedade, refletindo e ocupando espaço no campo das lutas das mulheres. É um processo que massifica e reduz todas as pautas e lutas a um discurso que está inscrito em um projeto de Classe que tem também Gênero e Etnia. Esse projeto distancia as mulheres da luta pela emancipação humana distribuindo para o Gênero feminino alguns avanços legais e a entrada em domínios antes vetados às mulheres como é o caso da educação, que aqui no Brasil, na década de 1990, assistiu a inversão das estatísticas escolares. Nesse campo as mulheres foram de uma posição de completa exclusão ao Gênero majoritário em todos os níveis de ensino.

No campo da política as mulheres ainda que subrepresentadas estão paulatinamente ocupando cargos políticos. No entanto a política institucional arquitetada nos jogos do poder e do lobismo, informa que as mulheres podem perfeitamente adentrar o campo da política sem acessar o poder político.

Além das questões estruturais que obstaculizam a emancipação feminina, as questões da conjuntura atual brasileira vêm nos mostrar de forma pungente que os direitos, antes de plenamente conquistados podem ser dissolvidos, que pactos sociais e as políticas públicas advindas destes podem implodir. Nesses cenários, as mulheres e, notadamente as mulheres negras, sentem os efeitos de forma mais virulenta.

Atualmente, podemos constatar que não apenas os movimentos feministas crescem, mas também crescem em igual proporção os movimentos conservadores e reacionários que defendem a neutralidade da educação e atacam a denominada ideologia de Gênero. Esta questão tem levado as mulheres às ruas, mobilizado muitos grupos, com o objetivo de questionar discussões e propostas do legislativo de muitos estados e municípios brasileiros, que estão defendendo um retrocesso e tentando retirar direitos conquistados por meio de muitas lutas.

\section{Considerações finais}


Na conjuntura atual, como se tentou discutir ao longo deste trabalho, é importante destacar que a luta das mulheres é também a luta contra o capitalismo, o racismo, a precarização do trabalho e, contra todas as formas de discriminação, em uma sociedade desigual e excludente.

No modo de produção capitalista o trabalho dos homens é mais valorizado que o das mulheres, e, nesta lógica, o capital utiliza o trabalho feminino e o converte em uma forma de ampliar ainda mais a desigualdade, à medida, que os "homens e as mulheres são diferentemente qualificados e capacitados para o ingresso no mercado de trabalho" e, o "capitalismo tem sabido apropriar-se desigualmente dessa divisão sexual do trabalho". (ANTUNES, 2000, p. 109-110). Isto se contata, à medida que o "capital tem sabido também se apropriar intensificadamente da polivalência e multiatividade do trabalho feminino", ainda, da experiência que as "mulheres trabalhadoras trazem das suas atividades realizadas na esfera do trabalho doméstico".

No que se relaciona à educação das mulheres, ao entrincheirar a educação com suas ideias e ideais de família, de Gênero feminino, tanto os organismos internacionais quanto a ideologia da Classe dominante, deixam transparecer a importância que a educação tem para a manutenção do status quo e por isso impedem por meio de diferentes estratégias o acesso universal a esse direito, restringindo em quantidade e qualidade a educação de determinada classe, gênero e etnia. Ao passo que, de forma perversa, vendem a ideia de que a educação irá erradicar todos os males da humanidade.

O ideário apresentado pelo Banco Mundial, por exemplo, é bastante claro no que diz respeito a estas questões ao sublinhar que: "aumentar as oportunidades econômicas das mulheres é uma das formas mais poderosas para fazer crescer a econômica global". Assim, a estratégia de Gênero do Grupo Banco Mundial concentra o trabalho em cobrir as lacunas restantes no acesso à educação e à saúde materna nos países em que persiste essa lacuna". (BM. 2017, p. 22).

Ao partir do caráter emancipador da educação, as mulheres iniciam por essa esfera suas lutas, no entanto, não se ignoram os limites da educação 
formal nessa sociedade que necessita da alienação para se reproduzir, mas também se defende que sem acesso à educação a luta das mulheres não

avança. É exatamente a partir de tal constatação que as mulheres lutam pelo direito à educação, escondendo seus livros debaixo de seus véus como fazem as meninas sob o regime Talibã, ou enfrentando duplas ou triplas jornadas sem abandonarem os estudos como nos mostram as mulheres ocidentais, pois, a luta e a esperança são palavras femininas.

\section{Referências}

ANTUNES, Ricardo. Os sentidos do trabalho: Ensaio sobre a afirmação e a negação do trabalho. São Paulo: Boitempo, 2000.

BANCO MUNDIAL. Relatório sobre o desenvolvimento mundial de Igualdade de Gênero e Desenvolvimento. H Street, NW Washington D.C. 2011. Disponível em:( www.worldbank.org). Acesso em: 19 jun.2018.

Relatório Anual 2017. End Poverty. Disponível em:

(https://openknowledge.worldbank.org/bitstream/handle/10986/27986/21111 9PT.pdf.) Acesso em: 18 jun.2018.

CASTELLS, Manuel. Fim de Milênio. 5. ed. São Paulo: Paz e Terra, 1999.

CONNELL, Raewyn e PEASE, Rebecca. Gênero: uma perspectiva global. Nversos: São Paulo, 2015.

ENGELS, Friedrich. A origem da família e da propriedade privada e do Estado. Rio de Janeiro: Bertrand Brasil, 1997.

FOUGEYROLLAS-SCHWEBEL, Dominique. Movimentos Feministas. In: HIRATA, Helena, LABORIE, Françoise, DOARÉ, Hélène Le, SENORTIER, Danièle. (Org.). Dicionário Crítico do Feminismo. São Paulo: UNESP, 2009, p. $144-148$.

FURTADO, Celso. O Capitalismo Global. 7. ed., São Paulo: Paz e Terra, 1998.

HIPÓLITO Álvaro Moreira: Trabalho docente, classe social e relações de gênero. São Paulo: Papirus, 1997.

IANNI, Otavio. Introdução A produção da sociedade capitalista. In: MARX: sociologia. 6. ed. São Paulo: Ática, 1988. p. 7-42.

MARX, Karl; ENGELS, Friedrich. A ideologia Alemã. São Paulo: Grijalbo, 1977. 
MÉSZAROS, István. O poder da ideologia. Boitempo: São Paulo, 2014.

PERROT, Michelle. Minha história das mulheres. Contexto: São Paulo: 2015.

RAGO, Margareth. Feminismo e subjetividade em tempos pós-modernos. In: COSTA, Cláudia de Lima; SCHMIDT, Simone Pereira. (Org.). Poéticas e políticas feministas. Santa Catarina: Mulheres, 2004.

SOLNIT, Rebecca. A mãe de todas as perguntas: reflexões sobre os novos feminismos. Companhia das Letras: São Paulo, 2017.

STUART MILL, John. A sujeição das mulheres. São Paulo: Escala, 2006.

WOOLF, Virgínia. Um teto todo seu. São Paulo: Tordesilhas, 2014.

WOLLSTONECRAFT, Mary. Reinvindicação dos direitos das mulheres. São Paulo: Edipro, 2015.

YOUSAFZAI, Malala. Eu sou Malala: a história da garota que defendeu o direito à educação e foi baleada pelo Talibã. São Paulo: Companhia das Letras, 2013.

Recebido em fevereiro de 2019.

Aprovado em abril de 2019. 